\title{
Klasifikasi Rating Otomatis pada Dokumen Teks Ulasan Produk Elektronik Menggunakan Metode $N$-gram dan Nä̈ve Bayes
}

\author{
Rahmawan Bagus Trianto', Andri Triyono², Dhika Malita Puspita Arum³ \\ 1,2,3 Ilmu Komputer, Fakultas Sains dan Kesehatan, Universitas An Nuur, Jl. Gajah Mada No.7, Majenang, \\ Kuripan, Kec. Purwodadi, Kabupaten Grobogan, 58112 \\ e-mail: ${ }^{1}$ rahmawanbagust@gmail.com, ${ }^{2}$ andritriyono1@ gmail.com, ${ }^{3}$ dhika.malita.11@gmail.com
}

Submitted Date: August $20^{\text {th }}, 2020$

Revised Date: September $28^{\text {th }}, 2020$
Reviewed Date: September 22 2020

Accepted Date: September $30^{\text {th }}, 2020$

\begin{abstract}
Online product ratings usually provide descriptive reviews and also reviews in the form of ratings. Likewise, what was done at the Lazada online store. Descriptive review can provide a clear view compared to a rating review to other potential buyers. However, in reality there is a mismatch between the description review and the rating given. This creates a lack of information for sellers as well as potential buyers. Automatic classification of buyer descriptive reviews is proposed in this study so that there is a match between descriptive reviews and rating reviews. This automatic classification descriptive review uses the Naive Bayes algorithm with $n$-gram feature extraction and TF-IDF word weighting. The results of this study obtained the best accuracy of $94.06 \%$, a recall of $91.73 \%$ and precision of $90.71 \%$ in Bigram feature extraction. With this accuracy value it can be used as a reference or model for classifying product description reviews, so that the feedback process between sellers and buyers can run well.
\end{abstract}

Keywords: Electronic product review; Classification; Naïve Bayes; n-gram; TF-IDF

\section{Abstrak}

Penilaian produk online biasanya dengan memberikan ulasan deskripsi dan juga ulasan berupa rating. Begitu juga yang dilakukan pada toko online Lazada. Ulasan deskripsi dapat memberikan pandangan yang jelas dibandingkan dengan ulasan berupa rating kepada calon pembeli lain. Namun pada kenyataannya sering dijumpai ketidaksesuaian antara ulasan deskripsi dengan rating yang diberikan. Hal ini membuat kurangnya informasi bagi penjual dan juga calon pembeli. Pengklasifikasian otomatis ulasan deskripsi pembeli diusulkan pada penelitian ini agar terjadi kesesuaian antara ulasan deskripsi dengan ulasan rating. Pengklasifikasian otomatis ulasan deskripsi ini menggunakan algoritma Naive Bayes dengan ekstraksi fitur n-gram dan pembobotan kata TF-IDF. Hasil dari penelitian ini didapatkan akurasi terbaik sebesar 94.06\%, recall sebesar $91.73 \%$ dan presisi sebesar $90.71 \%$ pada ekstraksi fitur Bigram. Dengan nilai akurasi yang cukup tinggi tersebut dapat dijadikan salah satu acuan atau model untuk mengklasifikasikan ulasan deskripsi produk, sehingga proses umpan balik antara penjual dan pembeli dapat berjalan dengan baik.

Kata kunci: Ulasan produk elektronik; Klasifikasi; Nä̈ve Bayes; $n$-gram; TF-IDF

\section{Pendahuluan}

Belanja online sudah dikenal banyak orang karena memiliki banyak keunggulan. Beberapa alasan orang berbelanja online adalah tidak perlu datang ke toko, harga relatif rendah, tidak perlu antri, tidak perlu bermacet-macetan di jalan (Harahap, 2018). Dan sekarang dengan adanya wabah covid-19 yang mengharuskan masyarakat harus menerapkan protokol kesehatan secara benar, maka belanja online menjadi salah satu pilihan terbaik (Hardilawati, 2020). Jual beli secara online sudah tentu memberikan pengalaman yang berbeda jika dibandingkan dengan cara konvensional. Perbedaan pengalaman berbelanja tersebut seperti tidak dapat melihat dan mencoba produk aslinya. Maka, untuk dapat menilai produk yang dijual secara online biasanya digunakan fitur ulasan. Dengan ulasan yang ditulis oleh pembeli maka akan sangat membantu bagi calon pembeli untuk memutuskan berbelanja. Selain itu, ulasan juga 
sangat penting bagi penjual, karena dapat digunakan untuk meningkatkan kualitas penjualannya di masa yang akan datang (Farki, Baihaqi, \& Wibawa, 2016).

Produk elektronik semakin diperlukan di era teknologi seperti sekarang, mulai dari komputer, smartphone, TV, peralatan internet, laptop, dan lain-lain. Banyak produk elektronik yang beredar luas di pasaran, terutama toko online seperti Lazada. Lazada merupakan salah satu e-commerce terbesar yang ada di Indonesia dengan berbagai produk yang dijualnya. Salah satu jenis produk yang dijual adalah barang elektronik. Banyak ulasan dari pembeli untuk menilai kualitas barang, kualitas pelayanan penjual sampai pada kualitas pengiriman barang. Namun, fakta di kenyataan menunjukkan bahwa tidak semua pembeli memberikan ulasannya, baik berupa rating maupun secara deskripsi. Rating merupakan bentuk dari tingkat kepuasan orang yang melakukan belanja berupa ulasan setelah membeli suatu produk. Hal ini mengakibatkan informasi terkait produk tidak dapat diterima secara utuh, sehingga dapat mempengaruhi calon pembeli untuk melakukan transaksi pembelian (Sapuhtra, Fauzi, \& Rahayudi, 2019). Selain itu, pada kenyataan di lapangan tidak sedikit dijumpai adanya ulasan yang tidak sesuai antara deskripsi dan rating yang diberikan (Farki et al., 2016). Oleh sebab itu dibutuhkan sistem untuk dapat mengklasifikasikan ulasan pembeli ke dalam rating yang sesuai secara otomatis.

Pada penelitian sebelumnya, membahas mengenai klasifikasi untuk mendeteksi dua buah kelas ulasan, yaitu spam atau bukan spam, menggunakan Naïve Bayes dan ekstraksi fitur $n$ gram. Penggunaan ekstraksi fitur $n$-gram pada metode Nä̈ve Bayes terbukti dapat meningkatkan akurasi hingga $80.44 \%$ (Setyaji, Zidny, Prabowo, \& Hertantyo, 2018). Kemudian penelitian selanjutnya tentang klasifikasi teks pengaduan online menggunakan metode $n$-gram dan Neighbor Weighted K-Nearest Neighbor (WM K-NN), di mana penggunaan ekstraksi fitur $n$-gram yaitu unigram tidak memiliki pengaruh yang berarti. Dengan hasil rata-rata $f$-measurement sebesar $75.25 \%$, sama dengan algortima WM K-NN saja tanpa menggunakan ekstraksi fitur $n$-gram (Prasanti, Fauzi, \& Furqon, 2018). Penelitian lain tentang prediksi rating pada review produk kecantikan menggunakan metode Semantic Orientation Calculator dan Regresi Linier menggunakan ekstraksi fitur n-gram. Hasil penelitian ini menunjukkan ekstraksi firut $n$-gram, yaitu bigram dan trigram memiliki pengaruh dalam meningkatkan akurasi prediksi (Sapuhtra et al., 2019). Pada penelitian selanjutnya tentang prediksi rating otomatis menggunakan metode Nä̈ve Bayes dan $n$-gram pada ulasan produk kecantikan. Pada penelitian ini menghasilkan nilai akurasi terbaik dengan menggunakan kombinasi unigram dan bigram pada metode Nä̈ve Bayes dengan akurasi mencapai 97\% (Pujadayanti, Fauzi, \& Sari, 2018). Penelitian selanjutnya mengenai analisis pengaruh stemmer pada Bahasa Indonesia terhadap sentiment terjemahan ulasan film. Pada penelitian ini menyatakan bahwa stemming tidak memiliki pengaruh pada akurasi, bahkan cenderung mengurangi efisiensi dari analisis sentiment (Agastya, 2018).

Berdasarkan uraian di atas, maka peneliti mengusulkan sebuah penelitian dengan judul Klasifikasi Rating Otomatis pada Dokumen Teks Ulasan Produk Elektronik Menggunakan Metode $\mathrm{N}$-gram dan Naïve Bayes. Adapun ekstraksi fitur $n$-gram ini digunakan untuk meningkatkan akurasi klasifikasi pada metode Naüve Bayes, yaitu unigram, bigram, dan trigram. Penelitian ini juga tidak menggunakan proses stemming pada tahap preprocessing karena tidak memberikan pengingkatan yang signifikan terhadap performa. Tujuan dari penelitian ini adalah membuat model klasifikasi rating otomatis untuk memudahkan penjual dalam meningkatkan kualitas penjualan dan memberikan pertimbangan bagi calon pembeli di e-commerce untuk memutuskan dalam bertransaksi.

\section{Metode Penelitian}

\subsection{Data}

Penelitian ini menggunakan dataset terbuka yang dapat diakses oleh siapa saja. Dataset ini diambil dari alamat https://www.kaggle.com/grikomsn/lazada-

indonesian-reviews. Dataset ini berkaitan dengan ulasan dari pembeli di e-commerce Lazada untuk jenis barang elektronik. Data yang diambil untuk penelitian ini sebanyak 10.000 baris dengan kolom reviewContent, yaitu berupa data teks komentar dan rating. Rating terdiri dari angka yang dimulai dari 1 sampai dengan 5. Kolom rating merupakan jenis data label dalam pembelajaran terarah atau biasa disebut dengan supervised learning. Data diambil secara acak untuk menghindari kemungkinan subyektifitas yang terjadi. 


\subsection{Metode yang Diusulkan}

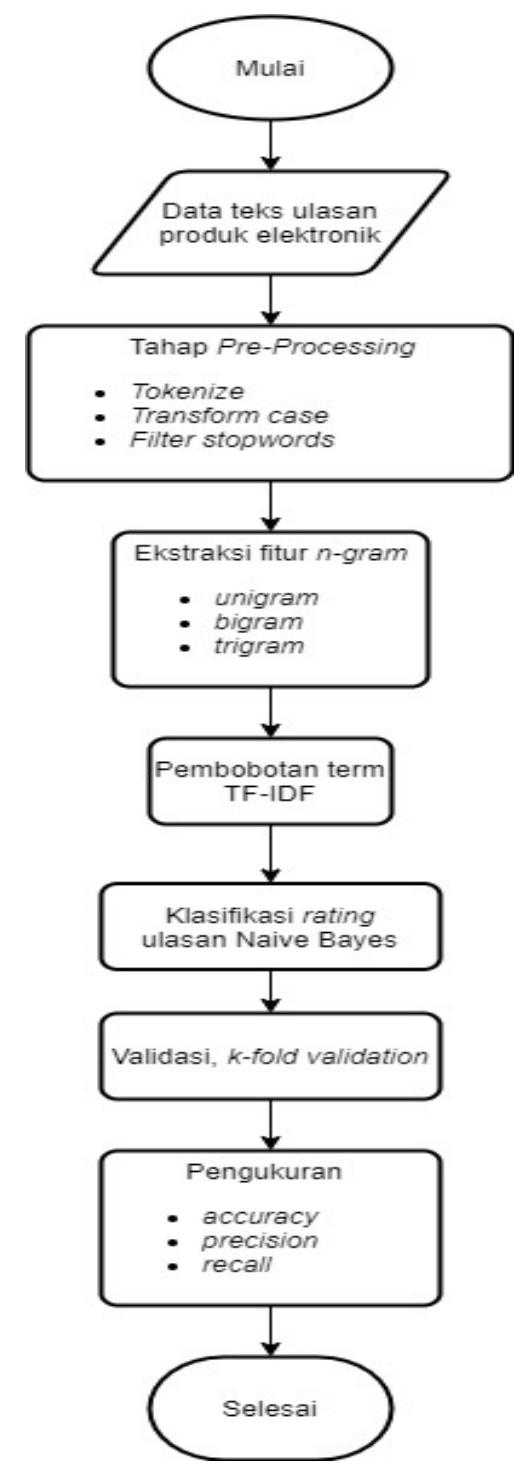

Gambar 1. Flowchart metode yang diusulkan

Tahap pertama pada proses klasifikasi rating ulasan dilakukan pre-processing. Pada tahap preprocessing ini terdiri dari tiga proses, yaitu tokenize, transform case dan filter stopwords. Setelah melalui tahap pre-processing dilanjutkan dengan ekstraksi fitur. Ekstraksi fitur pada penelitian ini menggunakan n-gram, yaitu unigram, bigram dan trigram. Selanjutnya masuk ke tahap pembobotan term atau pembobotan kata menggunakan TF-IDF. Setelah didapatkan bobot masing-masing kata, dilanjutkan pada proses klasifikasi menggunakan metode Nä̈ve Bayes dan dilakukan validasi menggunakan $k$-fold validation. Validasi menggunakan $k$-fold validation dengan nilai $k=10$. Selanjutnya dilakukan evaluasi dengan pengukuran $F$-Measure untuk mengetahui akurasi, presisi dan juga recall.

\subsection{Tahap Pre-Processing}

Langkah awal yang dilakukan dalam memproses dokumen teks adalah pre-processing. Proses yang dilakukan seperti tokenize, yaitu memecah kalimat menjadi bentuk yang lebih sederhana, yaitu kata atau dikenal dengan nama term (García Adeva, Pikatza Atxa, Ubeda Carrillo, \& Ansuategi Zengotitabengoa, 2014). Transform case atau mengubah huruf ke dalam bentuk huruf kecil juga dilakukan pada tahap pre-processing ini (García Adeva et al., 2014). Tahap yang tidak kalah penting adalah filter stopwords, yaitu membuang informasi yang tidak relevan, tidak penting dan tidak dibutuhkan dalam suatu dokumen teks (Sheela, 2018). Pada penelitian ini tidak menggunakan tahap stemming karena pada penelitian (Agastya, 2018) tidak menunjukkan adanya perbaikan hasil akhir, bahkan menambah beban pada komputer karena membutuhkan waktu dan sumber daya yang lebih banyak.

\subsection{N-Gram}

Dalam suatu dokumen teks, bahasa atau ungkapan tidak hanya tersusun dari kata-kata parsial. Namun untuk membentuk makna yang sebenarnya bahasa atau ungkapan terdiri dari gabungan dua kata atau lebih. Gabungan dua kata atau lebih ini dalam text mining dikenal dengan nama $n$-gram (Pujadayanti et al., 2018) (Lidya, Sitompul, \& Efendi, 2015). Sebagai contoh penggunaan $n$-gram dengan $n=2$ pada kalimat "Laptop sampai dengan selamat, pelayanan penjual memuaskan, pengiriman sangat cepat" adalah "laptop sampai", "sampai dengan", "dengan selamat", "pelayanan penjual”, "penjual memuaskan", "pengiriman sangat", "sangat cepat". Jika menggunakan $n=3$ maka kalimat dipecah setiap tiga kata.

\subsection{Pembobotan Term TF-IDF}

Term Frequency - Inverse Document Frequency atau sering dikenal dengan TF-IDF adalah teknik gabungan dari TF dan IDF untuk memberikan bobot dari term (Haq \& Budi, 2019). TF-IDF sangat terkenal digunakan untuk pemrosesan bahasa alami (Trstenjak, Mikac, \& Donko, 2014). Selain itu TF-IDF juga sangat baik dalam menentukan term penting dalam dokumen teks (AL-Smadi, Jaradat, AL-Ayyoub, \& Jararweh, 2017). Untuk mendapatkan bobot term dapat dilihat pada persamaan 1 . 


$$
T F * I D F(d, t)=T F(d, t) * \log \frac{N}{d f(t)}
$$

Untuk:

- $\quad \mathrm{TF} * \operatorname{IDF}(\mathrm{d}, \mathrm{t})=$ bobot term $t$ pada dokumen $d$

- $\mathrm{TF}(\mathrm{d}, \mathrm{t})=$ frekuensi kemunculan term $\mathrm{t}$ pada dokumen $d$

- $\mathrm{N}=$ total seluruh dokumen

- $\operatorname{df}(\mathrm{t})=$ jumlah dokumen yang terdapat term $t$

\subsection{Klasifikasi dengan Nä̈ve Bayes}

Klasifikasi telah dipakai dalam berbagai bidang, salah satunya pada konteks dokumen. Klasifikasi dokumen teks sudah dipakai seperti pengelompokan jenis dokumen, klasifikasi spam atau bukan spam pada pesan elektronik, menentukan sentiment positif dan negatif, serta masih banyak lagi (Di Nunzio, 2014). Salah satu metode yang banyak digunakan untuk klasifikasi adalah Naïve Bayes. Metode Nä̈ve Bayes merupakan metode klasifikasi berdasarkan teorema probabilitas dan statistik Bayes (Haq \& Budi, 2019) (Santoso et al., 2020). Nä̈ve Bayes dapat memperkirakan peluang yang mungkin terjadi di masa depan dengan melihat data-data sebelumnya dengan ciri khas berupa independensi dari masingmasing kondisi. Rumus Nä̈ve Bayes dapat dilihat secara matematisnya pada persamaan 2 .

$P(C \mid X)=\frac{P(c \mid X) * P(c)}{P(x)}$

\section{Untuk:}

- $\mathrm{x}=$ data yang belum diketahui kelasnya

- $\mathrm{c}=$ data yang telah diketahui kelasnya

- $\mathrm{p}(\mathrm{c} \mid \mathrm{x})=$ peluang hipotesis $\mathrm{c}$ berdasarkan kondisi $\mathrm{x}$ (posterior probability)

- $\mathrm{p}(\mathrm{x} \mid \mathrm{c})=$ peluang hipotesis $\mathrm{x}$ berdasarkan kondisi c (likelihood)

- $\mathrm{p}(\mathrm{c})=$ peluang hipotesis $\mathrm{c}$ (class prior probability)

- $\mathrm{p}(\mathrm{x})=$ peluang $\mathrm{x}$ (predictor prior probability)

Sedangkan untuk klasifikasi dengan data yang berlanjut digunakan persamaan 3 .

$P\left(A_{i} \mid C_{j}\right)=\frac{1}{\sqrt{2 \pi \sigma_{i j}}} \exp ^{-\frac{\left(A_{i}-\mu_{i j}\right)^{2}}{2\left(\sigma_{i j}\right)^{2}}}$
Untuk:

- $\quad \mathrm{P}=$ peluang

- $\mathrm{A}_{\mathrm{i}}=$ atribut ke $\mathrm{i}$

- $\mathrm{C}=$ kelas yang akan diklasifikasikan

- $\sigma=$ varian seluruh atribut

- $\mu=$ rata-rata seluruh atribut

Adapun pengujian pada penelitian ini menggunakan $k$-fold validation dengan nilai $k=10$, yang berarti data akan dibagi menjadi 10 bagian dan setiap 9 bagian akan dipakai sebagai data learning atau pelatihan, dan 1 bagian dipakai sebagai data testing atau pengujian (Saputri, Mahendra, \& Adriani, 2019).

\subsection{Validasi dan Pengukuran Performa}

Validasi yang digunakan pada penelitian ini adalah $k$-fold validation dengan $k=10$. Ini berarti dataset dipecah menjadi 10 bagian, 9 bagian digunakan untuk proses pelatihan dan 1 bagian digunakan untuk proses pengujian. Proses ini dilakukan sebanyak 10 kali (Wahono, Herman, \& Ahmad, 2014). Tahap ini dapat dilihat pada tabel 1.

Tabel 1. Pembagian dataset pada 10-fold validation

\begin{tabular}{|c|l|l|l|l|l|l|l|l|l|l|}
\hline $\begin{array}{l}\text { Validasi } \\
\text { ke-n }\end{array}$ & \multicolumn{7}{|c|}{ Pembagian dataset } \\
\hline 1 & & & & & & & & & & \\
\hline 2 & & & & & & & & & & \\
\hline 3 & & & & & & & & & & \\
\hline 4 & & & & & & & & & & \\
\hline 5 & & & & & & & & & & \\
\hline 6 & & & & & & & & & & \\
\hline 7 & & & & & & & & & & \\
\hline 8 & & & & & & & & & & \\
\hline 9 & & & & & & & & & & \\
\hline 10 & & & & & & & & & & \\
\hline
\end{tabular}

Tanda warna hitam menandakan dataset yang dipakai untuk data pelatihan. Sedangkan pada bagian yang lain menandakan dataset yang dipakai untuk data pelatihan.

Untuk mengetahui performa klasifikasi, diperlukan sebuah pengukuran, yaitu akurasi, presisi dan recall (Deolika, Kusrini, \& Luthfi, 2019). Pengukuran ini sering dikenal dengan sebutan confusion matrix. Confusion matrix biasa dipakai pada proses pembelajaran terarah. Pada confusion matrix, data pada kolom mewakili data yang diharapkan, sedangkan data pada baris mewakili data yang diprediksi (Dhande \& Patnaik, 2014). Berbeda dengan klasifikasi dengan 2 buah 
kelas, untuk menghitung akurasi, presisi dan recall pada klasifikasi dengan kelas lebih dari 2 menggunakan rata-rata (Sokolova \& Lapalme, 2009). Untuk menghitung akurasi, presisi dan recall dapat dilihat pada persamaan 4, 5 dan 6 .

$$
\begin{aligned}
& \text { Akurasi }=\frac{\sum_{i=1}^{c} \frac{T P i+T N i}{T P i+T N i+F P i+F N i}}{c} * 100 \% \\
& \text { Presisi }=\frac{\sum_{i=1}^{c} T P i}{\sum_{i=1}^{c}(F P i+T P i)} * 100 \% \\
& \text { Recall }=\frac{\sum_{i=1}^{c} T P i}{\sum_{i=1}^{c}(T P i+F N i)} * 100 \%
\end{aligned}
$$

Di mana:

- $\mathrm{c}=$ jumlah kelas

- $\mathrm{TPi}=$ jumlah True Positive pada kelas ke i, jumlah data positif yang diklasifikasikan benar oleh sistem pada kelas ke i

- $\mathrm{TNi}=$ jumlah True Negative pada kelas ke i, jumlah data negatif yang diklasifikasikan benar oleh sistem pada kelas ke $\mathrm{i}$

- $\quad \mathrm{FNi}=$ jumlah False Negative pada kelas ke i, jumlah data negatif yang diklasifikasikan salah oleh sistem pada kelas ke $\mathrm{i}$

- $\quad \mathrm{FPi}=$ jumlah False Positive pada kelas ke i, jumlah data positif yang diklasifikasikan salah oleh sistem pada kelas ke $\mathrm{i}$

\section{Hasil dan Pembahasan}

Tabel 2. Hasil pengujian klasifikasi

\begin{tabular}{|l|c|c|c|}
\hline \multicolumn{1}{|c|}{ Model } & Akurasi & Presisi & Recall \\
\hline $\begin{array}{l}\text { Nä̈ve Bayes } \\
\text { tanpa } \text { n-gram }\end{array}$ & $85,66 \%$ & $77.92 \%$ & $87.28 \%$ \\
\hline $\begin{array}{l}\text { Naïve Bayes } \\
\text { dengan unigram }\end{array}$ & $85,66 \%$ & $77.92 \%$ & $87.28 \%$ \\
\hline $\begin{array}{l}\text { Naïve Bayes } \\
\text { dengan bigram }\end{array}$ & $\mathbf{9 4 , 0 6 \%}$ & $\mathbf{9 0 . 7 1 \%}$ & $\mathbf{9 1 . 7 3 \%}$ \\
\hline $\begin{array}{l}\text { Nä̈ve Bayes } \\
\text { dengan trigram }\end{array}$ & $89,91 \%$ & $79.29 \%$ & $91.48 \%$ \\
\hline
\end{tabular}

Tabel 2 menunjukkan hasil pengujian klasifikasi ulasan produk elektronik pada $e$ commerce Lazada. Hasil terbaik didapat pada pemakaian bigram pada metode Nä̈ve Bayes, yaitu dengan nilai akurasi sebesar $94.06 \%$, nilai presisi sebesar $90.71 \%$ dan nilai recall sebesar $91.73 \%$. Dapat dilihat pula bahwa pemakaian unigram tidak memiliki pengaruh sama sekali pada hasil klasifikasi jika dibandingkan dengan metode Nä̈ve Bayes saja, dibuktikan dengan nilai akurasi, presisi dan recall yang sama, yaitu masing-masing $85.66 \%, 77.92 \%$, dan $87.28 \%$. Hal ini karena penggunaan unigram pada dasarnya adalah sama saja dengan tahap pre-processing, yaitu pada tahap tokenize yang mana memecah kalimat menjadi kata-kata. Kemudian penggunaan trigram memberikan performa lebih baik jika dibandingkan dengan Naüve Bayes saja dan Nä̈ve Bayes + unigram, namun lebih rendah jika dibandingkan dengan Nä̈ve Bayes + bigram.

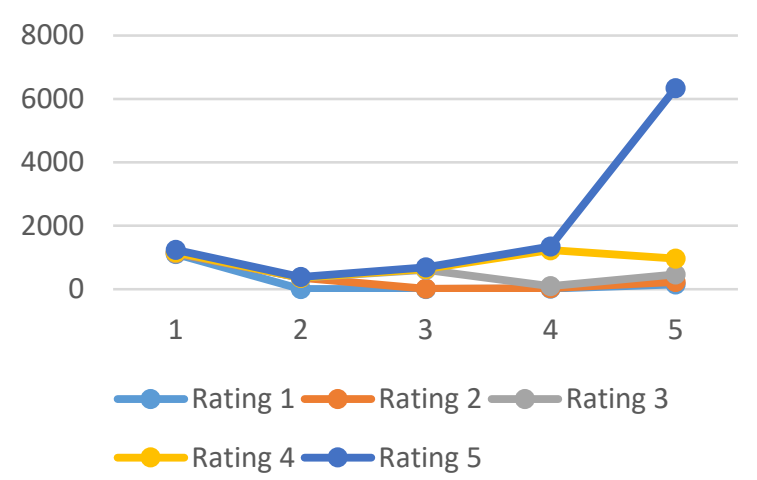

Gambar 2. Grafik sebaran klasifikasi Naïve Bayes dan Naïve Bayes + Unigram

Pada gambar 2 data sebaran rating pada hasil klasifikasi menggunakan Nä̈ve Bayes dan Nä̈ve Bayes + Unigram pada kelas rating 1 memiliki nilai yang benar sebanyak 1110 data, pada kelas rating 2 data yang benar sebanyak 347 . Pada kelas rating 3 memiliki data yang benar sebanyak 603, pada kelas rating 4 memiliki data yang benar sebanyak 1139 buah, serta pada kelas rating 5 memiliki nilai yang benar sebanyak 5367 buah data.

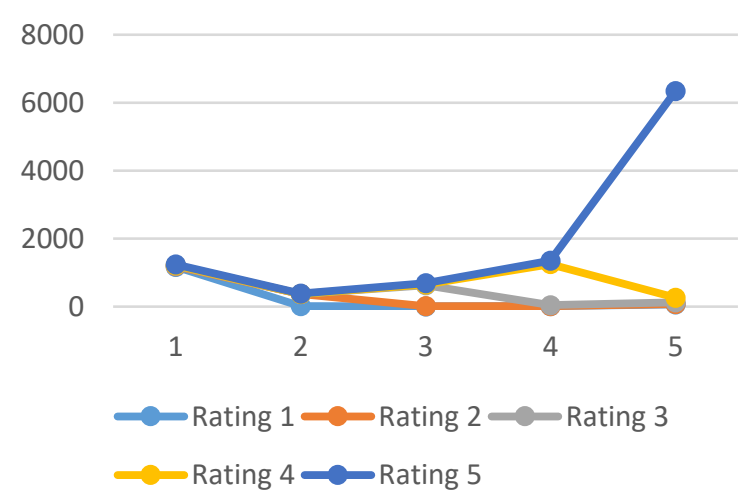

Gambar 3. Grafik sebaran klasifikasi Naïve Bayes + Bigram 
Pada gambar 3 dapat dilihat peningkatan hasil klasifikasi pada semua kelas rating jika dibandingkan dengan klasifikasi menggunakan Nä̈ve Bayes saja maupun Nä̈ve Bayes + Unigram, yaitu kelas rating 1 data yang benar sebanyak 1174, kelas rating 2 sebanyak 348, kelas rating 3 sebanyak 610, kelas rating 4 sebanyak 1203 dan kelas rating 5 sebanyak 6071 .

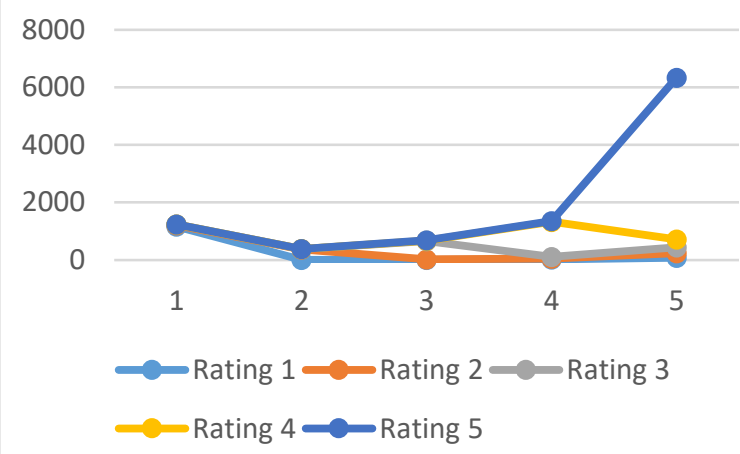

Gambar 4. Grafik sebaran klasifikasi Nä̈ve Bayes + Trigram

Gambar 4 menunjukkan hasil klasifikasi menggunakan Nä̈ve Bayes + Trigram, di mana semua kelas rating menunjukkan hasil yang lebih baik jika dibandingkan dengan Nä̈ve Bayes maupun Nä̈ve Bayes + Unigram. Jika dibandingkan dengan Nä̈ve Bayes + Bigram, hanya kelas rating 1 dan 5 yang memiliki data true positive lebih rendah, kelas rating 2, 3 dan 4 mempunyai data true positive lebih baik. Namun, pada kelas rating 2, 3 dan 4 tidak memiliki perbedaan yang besar. Pada kelas rating 5 memiliki perbedaan yang mencolok, dan ini salah satu sebab yang mengakibatkan akurasi, presisi dan recall menjadi lebih baik.

Pada pemakaian $n$-gram, terutama pada fitur bigram, dapat mengklasifikasikan lebih baik karena gabungan dua kata memberikan makna yang lebih baik, sehingga hasil klasifikasi juga menjadi lebih baik jika dibandingkan dengan gabungan dari tiga kata dan juga kata tunggal. Hal ini dapat dilihat seperti kalimat "Barang $O k$, kualitas bagus dengan harga yg cukup miring, kualitas gambar juga ok, pengiriman lumayan, ga nyesel pokonya beli TV ini", setelah melalui tahap pre-processing dan ekstraksi fitur maka menjadi "barang ok", "ok kualitas", "kualitas bagus", "bagus harga", "harga cukup", "cukup miring”, "miring kualitas", "kualitas gambar", "gambar ok", "ok pengiriman", "pengiriman lumayan", "lumayan ga", "ga nyesel", "nyesel pokonya", "pokonya beli", "beli tv". Dari gambar 2, 3 dan 4 dapat dilihat pula bahwa sebaran dataset yang diambil memiliki sifat imbalance dataset, yaitu ketidakmerataan jumlah data antar kelas, terutama pada kelas rating 5.

\section{Kesimpulan}

Klasifikasi ulasan produk elektronik ke dalam bentuk rating dapat dilakukan menggunakan metode Nä̈ve Bayes dan n-gram. Diawali dengan tahap pre-processing kemudian dilanjutkan pembobotan term menggunakan TF-IDF serta ekstraksi fitur menggunakan n-gram dan dilanjutkan klasifikasi menggunakan metode Nä̈ve Bayes. Ekstraksi fitur menggunakan n-gram terbukti dapat meningkatkan hasil akhir klasifikasi. Hasil terbaik yang didapatkan adalah menggunakan ekstraksi fitur bigram, diikuti ekstraksi fitur trigram dan setelahnya ekstraksi fitur unigram (dan juga hanya Nä̈ve Bayes tanpa $n$ gram). Adapun hasil akurasi, presisi dan recall pada klasifikasi dengan Nä̈ve Bayes menggunakan ekstraksi fitur bigram adalah sebesar 94.06\%, $90.71 \%$, dan $91.73 \%$. Dengan nilai akurasi yang cukup tinggi tersebut dapat dijadikan salah satu acuan atau model untuk mengklasifikasikan ulasan deskripsi produk, sehingga proses umpan balik antara penjual dan pembeli dapat berjalan dengan baik. Untuk hasil akurasi, presisi dan recall pada klasifikasi dengan Nä̈ve Bayes menggunakan ekstraksi fitur trigram sebesar 89.91\%, 79.29\% dan $91.48 \%$. Kemudian hasil akurasi, presisi dan recall pada klasifikasi dengan Nä̈ve Bayes menggunakan ekstraksi fitur unigram dan juga tanpa n-gram memiliki nilai yang sama, yaitu $85.66 \%, 77.92 \%$ dan $87.28 \%$.

\section{Referensi}

Agastya, I. M. A. (2018). Pengaruh Stemmer Bahasa Indonesia Terhadap Peforma Analisis Sentimen Terjemahan Ulasan Film. Jurnal Tekno Kompak, 12(1), 18. https://doi.org/10.33365/jtk.v12i1.70

AL-Smadi, M., Jaradat, Z., AL-Ayyoub, M., \& Jararweh, Y. (2017). Paraphrase identification and semantic text similarity analysis in Arabic news tweets using lexical, syntactic, and semantic features. Information Processing \& Management, 53(3), $640-652$ https://doi.org/10.1016/j.ipm.2017.01.002

Deolika, A., Kusrini, K., \& Luthfi, E. T. (2019). Analisis Pembobotan Kata Pada Klasifikasi Text Mining. Jurnal Teknologi Informasi, 3(2), 179. https://doi.org/10.36294/jurti.v3i2.1077

Dhande, L. L., \& Patnaik, P. G. K. (2014). Analyzing Sentiment of Movie Review Data using Naive Bayes Neural Classifier. International Journal of 
Emerging Trends \& Technology in Computer Science (IJETTCS), 3(4), 313-320. Diambil dari www.ijettcs.org

Di Nunzio, G. M. (2014). A new decision to take for cost-sensitive Naïve Bayes classifiers. Information Processing \& Management, 50(5), 653-674. https://doi.org/10.1016/j.ipm.2014.04.008

Farki, A., Baihaqi, I., \& Wibawa, M. (2016). Pengaruh online customer review rating terhadap kepercayaan place di indonesia. Jurnal Teknik ITS, 5(2), A614-A619.

García Adeva, J. J., Pikatza Atxa, J. M., Ubeda Carrillo, M., \& Ansuategi Zengotitabengoa, E. (2014). Automatic text classification to support systematic reviews in medicine. Expert Systems with Applications, 41(4), 1498-1508. https://doi.org/10.1016/j.eswa.2013.08.047

Haq, F. I. N., \& Budi, E. (2019). Implementasi Naive Bayes Classifier untuk Prediksi Kepribadian Big Five pada Twitter Menggunakan Term FrequencyInverse Document Frequency ( TF-IDF ) dan Term Frequency-Relevance Frequency ( TF-RF ) Program Studi Sarjana Ilmu Komputasi Fakultas Informatik. e-Proceeding of Engineering, 6(2), 9785-9795.

Harahap, D. A. (2018). Perilaku Belanja Online Di Indonesia: Studi Kasus. JRMSI - Jurnal Riset Manajemen Sains Indonesia, 9(2), 193-213. https://doi.org/10.21009/jrmsi.009.2.02

Hardilawati, W. L. (2020). Jurnal Akuntansi \& Ekonomika. Jurnal Akuntansi \& Ekonomika, 10(1), 89-98. Diambil dari http://ejurnal.umri.ac.id/index.php/jae

Lidya, S. K., Sitompul, O. S., \& Efendi, S. (2015). Sentiment Analysis Pada Teks Bahasa Indonesia Menggunakan Support Vector Machine ( Svm ). Seminar Nasional Teknologi dan Komunikasi 2015, 2015(Sentika), 1-8.

Prasanti, A. A., Fauzi, M. A., \& Furqon, M. T. (2018). Klasifikasi Teks Pengaduan Pada Sambat Online Menggunakan Metode N- Gram dan Neighbor Weighted K-Nearest Neighbor ( NW-KNN ). Jurnal Pengembangan Teknologi Informasi dan Ilmu Komputer (J-PTIIK) Universitas Brawijaya, 2(2), 594-601.

Pujadayanti, I., Fauzi, M. A., \& Sari, Y. A. (2018). Prediksi Rating Otomatis pada Ulasan Produk Kecantikan dengan Metode Naïve Bayes dan N- gram. Jurnal Pengembangan Teknologi Informasi dan Ilmu Komputer (J-PTIIK), 2(11), 4421-4427.

Santoso, H. A., Rachmawanto, E. H., Nugraha, A., Nugroho, A. A., Setiadi, D. R. I. M., \& Basuki, R. S. (2020). Hoax classification and sentiment analysis of Indonesian news using Naive Bayes optimization. Telkomnika (Telecommunication Computing Electronics and Control), 18(2), 799806.

https://doi.org/10.12928/TELKOMNIKA.V18I2. 14744

Sapuhtra, B. D., Fauzi, M. A., \& Rahayudi, B. (2019). Prediksi Rating Pada Review Produk Kecantikan Menggunakan Metode Semantic Orientation Calculator dan Regresi Linier. Jurnal Pengembangan Teknologi Informasi dan Ilmu Komputer, 3(5), 4477-4483.

Saputri, M. S., Mahendra, R., \& Adriani, M. (2019). Emotion Classification on Indonesian Twitter Dataset. Proceedings of the 2018 International Conference on Asian Language Processing, IALP 2018, 90-95. IEEE. https://doi.org/10.1109/IALP.2018.8629262

Setyaji, M., Zidny, M., Prabowo, W. A., \& Hertantyo, G. B. (2018). Naive Bayes dengan Ekstraksi Fitur $\mathrm{N}$-gram dalam Mendeteksi Spam Ulasan Bahasa Indonesia. Proceedings on Conference on Electrical Engineering, Telematics, Industrial Technology, and Creative Media, 56-60.

Sheela, S. P. (2018). Sentiment Analysis and Prediction of Online Reviews with Empty Ratings. International Journal of Applied Engineering Research, 13(14), 11532-11539.

Sokolova, M., \& Lapalme, G. (2009). A systematic analysis of performance measures for classification tasks. Information Processing and Management, 45(4), 427-437. https://doi.org/10.1016/j.ipm.2009.03.002

Trstenjak, B., Mikac, S., \& Donko, D. (2014). KNN with TF-IDF based framework for text categorization. Procedia Engineering, 69, 1356-1364. Elsevier B.V. https://doi.org/10.1016/j.proeng.2014.03.129

Wahono, R. S., Herman, N. S., \& Ahmad, S. (2014). A comparison framework of classification models for software defect prediction. Advanced Science Letters, 20(10-12), 1945-1950. https://doi.org/10.1166/asl.2014.5640 